Kong. Res. J. 4(1) : 79-86, 2017

ISSN 2349-2694

Kongunadu Arts and Science College, Coimbatore.

\title{
VARIATIONS OF PROXIMAL COMPOSITION IN PILEA MICROPHYLLA (L.) LIEBM DUE TO DESICCATION AND REHYDRATION IMPACTS
}

\author{
Greeshma, G.M. and K. Murugan* \\ Plant Biochemistry and Molecular Biology Laboratory, \\ Department of Botany, University College, Trivandrum-695 034, Kerala, India. \\ *Email: harimurukan@gmail.com
}

\begin{abstract}
Water deficiency is the most significant abiotic stress factor for land plants. Most plants are unable to survive desiccation to the air dry state. There are however a few species from lower plant groups to flowering plants that tolerate desiccation known as resurrection plants. So, the present investigation was undertaken to study the biochemical changes in Pileamicrophylla against desiccation $(1,3,5$ and 7 days) and rehydration (30 min) stress. As an initial part of the study total sugar, protein and proline content were analyzed and showed a gradual decline during the stress periods. The SDS-PAGE analysis of protein indicated the disapperance of certain bands in the desiccated and rehydrated samples (7D) when compared to the control indicating the denaturation of proteins during stress. Similarly, the appearance of new bands (15kDa on 3D and 20 and $17 \mathrm{kDa}$ on the 5D) were noticed suggesting the formation of stress related proteins to tide over desiccation. The amount of free amino acids increased in P. microphylla, in pace with desiccation periods. Constitutive increase in the level of proline (the stress amino acid) accumulation is seen when compared with the control i.e., 6 fold higher than that of the control, after exposed to desiccation for 5 D. Increase in proline level relating to exposure time of desiccation stress suggests its role as osmolyte. Similarly, a reduction in chlorophyll level and an increase in carotenoid were also observed during stress. Decrease of total chlorophyll content was observed with duration of desiccation. The decrease in chlorophyll a and $b$ was recovered during rehydration up to $5 \mathrm{D}$. Further studies are warranted at molecular level in terms of stress proteins and genes involved in desiccation tolerance in this plant.
\end{abstract}

Keywords: Desiccation, amino acids, SDA-PAGE, rehydration, osmolyte.

\section{INTRODUCTION}

Most of the crop plants are sensitive to desiccation or drought. Except a small group of vascular angiosperm plants, termed resurrection plants. They have evolved unique mechanisms of desiccation tolerance and thus can tolerate severe water loss, and mostly adjust their water content with the relative humidity in the environment. They have the unique ability to survive months to years without water, lose most of the free water in their vegetative tissues, fall into anabiosis and upon rewatering, quickly regain normal activity. Thus, they are fundamentally different from other drought tolerant plants such as succulents or ephemerals, which cope up with drought by maintaining higher steady state water potential or via a short life cycle, respectively. Desiccation tolerant plants may be subdivided into homoiochlorophyllous and poikilochlorophyllous types (Tuba et al., 1998). During desiccation homoiochlorophyllous species retain their intact photosynthetic apparatus and chlorophyll content in a readily recoverable form, whereas in poikilochlorophyllous species desiccation results in the loss of chlorophyll, which must be resynthetized following rehydration.

The main goals of the present study are to delineate whether Pileamicrophylla display an oxidative burst in the time-course response to desiccation-rehydration and to elucidate the protective mechanisms underlying tolerance to drought. Pileamicrophylla (L.) Liebm. also known commonly as Artillery or Gun powder Plant. It is annual plant native to Floridaand belongs to the Urticaceae. The plant grows in extreme conditions of habitats. Direct sunlight causes the leaves to turn brown and fall off, so it prefers filtered light.

\section{MATERIALS AND METHODS}

\subsection{Desiccation treatment}

All the experimental Pilea microphylla samples were collected from the natural habitat. Before desiccation, the samples were fully hydrated. The samples were desiccated in a desiccator over PEG in a controlled environment chamber. The selected species were subjected to four different desiccation regimes $1 \mathrm{D}, 3 \mathrm{D}, 5 \mathrm{D}$ and 7 D. After the desiccation exposure a set of desiccated 
samples were subjected to rehydration for $30 \mathrm{~min}$. The samples were divided into two groups: desiccated and desiccated subsequently rehydrated. Control plants were maintained in an optimal water conditions in each case during the whole experimental period.

\subsection{Quantification of photosynthetic pigments}

Total chlorophylls were estimated by the method of Chappelle et al. (1992). The homogenate as centrifuged at $3000 \mathrm{rpm}$ for $5 \mathrm{~min}$. The aliquots were made up to $3 \mathrm{ml}$ by using $80 \%$ acetone and the absorbance was measured at 470, 648 and $664 \mathrm{~nm}$ spectrophotometrically against $80 \%$ acetone as blank.

\subsection{Estimation of sugars}

Sugar content of leaves was estimated by the method of Miller (1972).

\subsection{Quantification of total free amino acids}

Total free amino acids were determined using the method of Moore and Stein (1948). Free proline accumulation was determined using the method of Bates et al. (1973).

\subsection{Estimation of soluble proteins}

The soluble proteins were estimated by using the method of Lowry et al. (1951).

\subsection{Polyacrylamide gel electrophoresis (PAGE)}

Genei mini model slab gel apparatus was used to carry out PAGE following the method of Laemmli (1970) and Fairbanks et al. (1971).

\section{RESULTS AND DISCUSSION}

\subsection{Photosynthetic pigments}

\subsubsection{Chlorophylls}

The effect of desiccation and rehydration showed varied response on the chlorophyll content of P. microphylla as shown in Table 1. Decrease of total chlorophyll content was observed with increasing duration of desiccation. It showed that both chlorophyll $a$ and $b$ decreased and consequently affected chlorophyll $a+b$ and $a / b$ ratio and recovered or showed some recovery during rehydration up to $5 \mathrm{D}$ desiccated plant body.

Plants employ chlorophylls $a$ and $b$ and carotenoids to capture light for photosynthesis. Most of the pigments serve as an antenna complex and are involved in collecting and transferring light energy to the reaction centres, where chemical reactions occur. Chlorophyll $b$ is mainly involved in light harvesting and thus is predominantly found in the chlorophyll $a / b$ antenna proteins, whereas chlorophyll $a$ is closely associated with the reaction centre complexes (Georgieva et al., 2010). Carotenoids are associated with both antenna and reaction centre proteins, and have multiple functions in photosynthesis. Carotenoids play vital role by masking the chloroplast from photo-oxidative damage caused by high intensity of light. Xanthophylls can achieve photo-protection by quenching the excited state of chlorophyll harmlessly as heat (non-photochemical quenching) as well as scavenging any singlet oxygen, which might have been formed (Oliver et al., 2005). Concentrations and ratios of photosynthetic pigments, (i.e., chlorophyll $a$ and $b$, and carotenoids) are correlated to the irradiance experienced by plants in their natural habitat.

Plants that grow in low light often have greater amounts of chlorophyll $b$ and lead to reduced chlorophyll $a$ to $b$ ratio than plants from high irradiance sites, possibly to increase light capture efficiency (Anderson, 1986). Similarly, higher chlorophyll to carotenoid ratios in plants from shaded habitats when compared with species from well-lit environments, suggests a lesser need for photo-protection. Lower resurrection plants have high levels of light harvesting chlorophyll $a / b$ antenna protein complexes in comparison to vascular plants, suggesting shade acclimation (Beer et al., 2002).

The decrease in Chl $a+b$ content was mainly attributed to the destruction of $\mathrm{Chl} b$, which is more sensitive to stress than Chla (Ma et al., 1997b). The desiccation stress can contribute a decrease in total chlorophyll content of the plant, by increasing the activity of Chl degrading enzyme cholorophyllase (Rao and Rao, 1981), inducing the destruction of chloroplast structure and instability of pigment protein complexes (Singh and Dubey, 1995). Results obtained from this study indicate that chlorophyll $b$ is more susceptible to stress than chlorophyll $a$ and it will be an ideal marker of drought stress.

\subsubsection{Carotenoids}

Carotenoid content was gently elevated by desiccation and attained the maximum value on $5 \mathrm{D}$. This is another indication for antioxidant potential in plants. Compared to the corresponding control, carotenoid contents increased by desiccation in $P$. microphylla(Table 1). The photosynthetic apparatus in Pileamicrophyllamay be better protected from photo-damage. 
Carotenoids protect plants against photooxidation, by effectively quenching the excited triplet state of chlorophyll and singlet oxygen. Protection of the photosynthetic apparatus from excess light absorption requires carotenoids (oxygenated) (Horton et al., 1996). Similar to other resurrection plants, P. microphylla inhabit areas with high irradiances usually have a better developed photoprotective system, illustrated by its chlorophyll to carotenoid ratios (Marschall et al., 2004).

Pileamicrophylla studied here have acclimated to the levels of light available, within their habitat. Flowering plants from habitats with low radiation inputs had higher concentrations of photosynthetic pigments (i.e., chlorophyll and carotenoids) and higher chlorophyll to carotenoid ratios, than from sunny environments. Plants from shaded environments usually modify chlorophyll $a / b$ protein complexes to increase light harvesting, illustrated by a low chlorophyll $a$ to $b$ ratio (Leong et al., 1983).

This species had reduction in the amounts of photosynthetic pigments and chlorophyll $a$ to $b$ ratio (Table 1). This illustrates the need for an efficient light harvesting system, to collect all of the available light. The values are in accordance with other species, from extremely shaded environments (Marschallet al., 2004). The chloroplast distribution in such plantsshowed some remarkable features. The ventral side of the lamina is unlikely to be exposed to light, yet chloroplasts were found there. Such a feature could afford protection from environmental stress, since it allows preservation of functional chloroplasts on the ventral side, while the chloroplasts on the dorsal side are being damaged.

\subsubsection{Total soluble sugar}

In P. microphylla the level of sugar showed gradual decline from $1 \mathrm{D}$ of desiccation onwards indicating the depletion of stored carbohydrates into soluble sugars and its consumption (Table 2). Plants accumulate carbohydrates such as starch and fructans as storage substances that can be mobilized during periods of limited energy supply or enhanced energetic demands. While most plant species use starch as their main storage carbohydrate, several angiosperms, mainly from regions with seasonal cold and dry periods, accumulate fructans (Hendry, 1993). Accumulation of fructans might be advantageous, due to their high water solubility, their resistance to crystallization at freezing temperatures, and the fact that fructan synthesis functions normally under low temperatures
(Livingston et al., 2009). Furthermore, fructans can stabilize membranes and might indirectly contribute to osmotic adjustment upon freezing and dehydration by the release of hexose sugars (Spollen and Nelson, 1994; Olien and Clark, 1995). Many researchers like Basu et al. (2007); Kempa et al. (2008) has reported that salt and drought stress generally leads to a depletion of starch content and to the accumulation of soluble sugars in leaves. Sugars that accumulate in response to stress can function as osmolytes to maintain cell turgor and have the ability to protect membranes and proteins from stress damage (Kaplan and Guy, 2004).

\subsubsection{Total Soluble protein}

Soluble protein decreased significantly in both desiccated and also rehydrated plants that are imposed to stress (Table 3). Protein degradation might be the result of increased activity of protease or other catabolic enzymes, which were activated under desiccation stress, or due to fragmentation of proteins by the toxic effects of ROS resulting in reduced protein content (Davies, 1987). A decrease in the protein concentration would be a typical symptom of oxidative stress and has frequently been observed in drought stressed plants (Moran et al., 1994)

\subsubsection{Total free amino acids and proline content}

Total free amino acids and proline contents in P.microphylla are shown in the Table 4. The amount of free amino acids increased in $P$. microphylla, in pace with desiccation periods. Although the total amino acids are clearly built up in the species, their accumulation is more obvious during 5D of desiccation. Constitutive level of proline accumulation is also increased when compared with the control i.e., 6 fold higher than that of the control, after exposed to desiccation for 5 D. The proline content progressively enhanced, corresponding to desiccation period up to 5D. Increase in proline level relating to exposure time of desiccation stress suggests its role as osmolyte. The long exposure period $(7 \quad$ D) reduced the proline accumulation. There are three possible reasons for the free proline accumulation under stress- (1) stimulation of proline synthesis from glutamic acid (Girousseet al., 1996), which has been found to be dependent on the abscisic acid concentration; (2) inhibition of proline oxidation to other soluble compounds; (3) inhibition of protein synthesis. In contrast to its metabolism, the physiological significance of proline accumulation has been less studied (Sharma et al., 2006). 
Table 1. Chlorophyll a, $b$ and carotenoid content $\left(\mathrm{mg} \mathrm{g}^{-1} \mathrm{FW}\right)$ of the desiccated $(1,3,5$ and $7 \mathrm{D})$ and rehydrated plant body of $P$. microphylla. Data points represent means of three replicates and probability level at $P<0.01$.

\begin{tabular}{cccccccccc}
\hline Pigments & Control & 1 D & 1 R & 3 D & 3 R & 5 D & 5 R & 7 D & 7 R \\
\hline Chl $a$ & 4.2 & 2.98 & 3.6 & 2.26 & 3.72 & 1.92 & 3.67 & 1.8 & 2.56 \\
SE & 0.96 & 0.54 & 0.26 & 0.27 & 0.19 & 0.31 & 0.26 & 0.21 & 0.32 \\
Chl $b$ & 1.79 & 1.73 & 1.4 & 1.13 & 1.52 & 1.0 & 1.38 & 0.92 & 0.99 \\
SE & 0.57 & 0.55 & 0.50 & 0.47 & 0.56 & 0.51 & 0.45 & 0.44 & 0.33 \\
Caro & 0.80 & 1.1 & 1.0 & 1.2 & 1.0 & 1.2 & 0.98 & 0.64 & 0.73 \\
SE & 0.90 & 0.49 & 0.28 & 0.57 & 0.49 & 0.39 & 0.50 & 0.31 & 0.58 \\
F ratio & $1.96^{* *}$ & $7.8^{* *}$ & $12.6^{* *}$ & $14.9^{* *}$ & $10.8^{* *}$ & $8.9^{* *}$ & $7.6^{* *}$ & $3.9^{* *}$ & $4.8^{* *}$ \\
CD & 1.3 & 1.4 & 1.28 & 1.39 & 1.46 & 1.38 & 1.52 & 1.28 & 1.34 \\
\hline
\end{tabular}

Table 2. Influence of desiccation $(1,3,5$ and $7 \mathrm{D} ; \mathrm{D}=$ days) and rehydration on the levels of total sugar content $(\mu \mathrm{g} / \mathrm{g})$. The values are means of three individual experiments with duplicates and probability level at $P<0.01$.

\begin{tabular}{ccccc}
\hline Condition & 1 D & 3 D & 5 D & 7D \\
\hline Control & 21.11 & 19.89 & 20.67 & 21.68 \\
SE & 2.34 & 1.21 & 1.08 & 1.22 \\
Desiccation & 13.17 & 10.76 & 6.96 & 4.6 \\
SE & 1.42 & 1.08 & 1.07 & 0.28 \\
Rehydration & 17.2 & 16.04 & 12.83 & 12.5 \\
SE & 1.04 & 1.26 & 1.31 & 0.78 \\
F ratio & $2.85^{* *}$ & $3.52^{* *}$ & $3.69^{* *}$ & $4.85^{* *}$ \\
CD & 1.08 & 1.24 & 1.32 & 1.09 \\
\hline
\end{tabular}

Table 3. Influence of desiccation (1, 3, 5 and $7 \mathrm{D}$; $\mathrm{D}=$ days) and rehydration on the levels of total protein content $(\mathrm{mg} / \mathrm{g})$. The values are means of three individual experiments with duplicates and probability level at $P<0.01$.

\begin{tabular}{ccccc}
\hline Condition & 1 D & 3 D & 5 D & 7 D \\
\hline Control & 8.97 & 7.89 & 8.25 & 8.55 \\
SE & 1.24 & 0.66 & 0.92 & 1.00 \\
Desiccation & 6.2 & 4.3 & 3.24 & 1.87 \\
SE & 0.08 & 0.16 & 0.24 & 0.13 \\
Rehydration & 7.02 & 8.19 & 5.74 & 4.80 \\
SE & 1.24 & 0.29 & 1.01 & 0.76 \\
F ratio & $1.29^{* *}$ & $1.69^{* *}$ & $1.99^{* *}$ & $2.78^{* *}$ \\
CD & 1.07 & 0.98 & 0.29 & 1.08 \\
\hline
\end{tabular}

Table 4. Free amino acids, Proline, content of the desiccated $(1,3,5$ and $7 \mathrm{D})$ and rehydrated plant body of P.microphylla. Data points represent means of three replicates and probability level at $P<0.01$

\begin{tabular}{cccccccccc}
\hline & Control & 1 D & 1 R & 3 D & 3 R & 5 D & 5 R & 7 D & 7 R \\
\hline Free amino acids & 1.76 & 4.85 & 2.1 & 8.78 & 2.4 & 9.69 & 2.5 & 8.2 & 2.6 \\
$\left(\mu \mathrm{g} \mathrm{g}^{-1} \mathrm{FW}\right)$ & & & & & & & & \\
SE & 0.06 & 0.08 & 0.04 & 0.09 & 0.06 & 0.07 & 0.02 & 0.04 & 0.08 \\
F ratio & $1.3^{* *}$ & $1.4^{* *}$ & $1.7^{* *}$ & $1.9^{* *}$ & $1.2^{* *}$ & $1.49^{* *}$ & $1.8^{* *}$ & $1.98^{* *}$ & $1.29^{* *}$ \\
CD & 1.03 & 1.25 & 1.39 & 1.21 & 1.08 & 1.77 & 1.67 & 1.58 & 1.49 \\
Proline & 175.5 & 323 & 180.6 & 556 & 184.6 & 1038 & 190.3 & 696.5 & 190.6 \\
$\left(\mu \mathrm{g} \mathrm{g}^{-1} \mathrm{FW}\right)$ & 0.13 & 0.29 & 0.66 & 0.49 & 0.78 & 0.92 & 0.81 & 0.67 & 0.77 \\
SE & $1.6^{* *}$ & $2.4^{* *}$ & $1.38^{* *}$ & $1.39^{* *}$ & $1.66^{* *}$ & $1.69^{* *}$ & $1.28^{* *}$ & $1.39^{* *}$ & $1.45^{* *}$ \\
F ratio & 1.25 & 1.38 & 1.42 & 1.08 & 1.29 & 1.65 & 1.89 & 1.29 & 1.66 \\
CD & & & & & & & & & \\
\hline
\end{tabular}


In halophytes, salt tolerance associates with the capacity to accumulate proline, which acts as compatible solute, involved in osmotic adjustment at the plant cell level (Delauneyet al., 1993). It has been suggested that, the proline accumulation is due primarily to the function of both genes encoding $\Delta^{1}$ pyrroline-5-carboxylate reductase, and $\Delta^{1}$-pyrroline5-carboxylate synthetase (Delauneyet al., 1993). Eder et al. (1977) reported that decreased protein synthesis and/or increased protein hydrolysis in pearl millet seedling by salinity, could lead to the accumulation of free amino acids and proline. In the present study, proline accumulation is observed in $P$. Microphylla (Table 4). However, at higher duration of desiccation (above 5D) the plantwilted; this suggests that proline does not help in reducing dehydration damage in this species. Another compatible solute, glycine betaine also functions as an important osmoprotectant between the cytoplasm and vacuole (Chen et al., 2002). Furthermore, this compound can reduce lipid peroxidation and protect mitochondrial electron transport reactions from stress damage (Chen et al., 2002). Previous studies have reported that, increased glycine betaine contributed to overcome water and salt stress in leguminous plants (Girijaet al., 2002). For a better understanding of the role of this compatible solute in osmotic maintenance in P. microphylla, further studies are warranted.

The free amino acid content has been shown to increase under drought conditions in sorghum (Yadav et al., 2005). Similar results were obtained in pepper (Nathet al., 2005), coconut (Kasturibaiet al., 2000), wheat (Hamada, 2000) and ground nut (Asha et al., 2002). Free amino acid accumulation is more important to account for most of the changes in osmotic potential. The accumulation of free amino acids under stress at all the experimental species indicates the possibility of their involvement in osmotic adjustment (Yadav et al., 2005). Osmotic adjustment is one of the important mechanisms alleviating some of the detrimental effects of water stress (Morgan, 1984).

Similarly, increased proline accumulation was reported in water stressed sorghum (Yadav et al., 2005), bell pepper (Nathet al., 2005), wheat (Hamada, 2000) and in salt stressed Catharanthusroseus(Jaleel et al., 2007c). Increased proline in the stressed plants may be an adaptation to overcome the stress conditions. Proline accumulates under stressed conditions supplies energy for growth and survival and thereby helps the plant to tolerate stress (Chandrashekaret al.,
1996). Under abiotic stress like UV light the proline content showed an increase in wheat (Demir, 2000). $\mathrm{NaCl}$ stress showed increased proline content in rice (Lin et al., 2002) and peanut (Girijaet al., 2002). Proline accumulation in plants might have a scavenger role of ROS and also act as an osmolyte (Tripathi and Gaur, 2004). The reduced proline oxidase may be another reason for increasing proline accumulation. Many researchers suggested that, proline plays a pivotal role in imparting plants tolerance to stress that lower the water potential of ambient environment.

Abiotic stresses like salt, heavy metals/drought lead to an increased accumulation of proline in tobacco cells coupled with the $\gamma$-glutamyl kinase level (Larosaet al., 1991). So the induction of proline accumulation, in the present study is may be due to an activation of proline synthesis through the glutamate pathway involving $\gamma$-glutamyl kinase, glutamyl phosphate reductase and $\Delta^{1}$-pyrroline-5carboxylate reductase activities (Bray, 1990; Girijaet al., 2002; Fujita et al., 2003). The proline accumulation in desiccation-stressed bryophytes may be attributed to the increased level of $\gamma$ glutamyl kinase activity or decreased level of proline metabolizing enzymes, like proline oxidase. The present study coincides with earlier reports concerning water stress in plants (Fujita et al.,2003).

\subsubsection{Polypeptide banding pattern in SDS-PAGE}

Environmental stress affects the protein banding pattern to counteract the stress. In the present study, the desiccation tolerance nature of $P$. microphylla was also evaluated using SDS-PAGE (Fig. 1). On the $1 \mathrm{D}$ of desiccation 6 protein bands were formed with molecular mass of 38, 36, 28, 21, 15 and $12 \mathrm{kDa}$. While on rehydration for 30 mins in the $1 \mathrm{D}$ desiccated plant showed the disappearance of the 15 $\mathrm{kDa}$ band and appearance of a new faint band at 60 $\mathrm{kDa}$. Similar studies have been undertaken by earlier workers. Under stress condition the plant synthesize the heat shock proteins. The essential function of heat shock proteins is preventing aggregation and assisting refolding of non-active proteins under both normal and stress conditions (Hartl, 1996; Frydman, 2001).

In the $3 \mathrm{D}$ desiccated plants only 3 bands were noticed i.e., an intensified $15 \mathrm{kDa}$ band and new bands of 10 and $5 \mathrm{kDa}$. Meanwhile in the rehydrated plant along with the above 3 bands, 3 new bands at 21, 24 and $32 \mathrm{kDa}$ were observed.

In contrast to the above results, the $5 \mathrm{D}$ 
desiccated plants showed only two intensified bands at 20 and $17 \mathrm{kDa}$. The rehydrated plants along with above bands showed two faint bands at 15 and 10 $\mathrm{kDa}$. Ali and Basha (1998) showed that the total protein content of the leaves significantly increased when peanut plants were subjected to water stress for 5 to 20 as compared to irrigated controls.

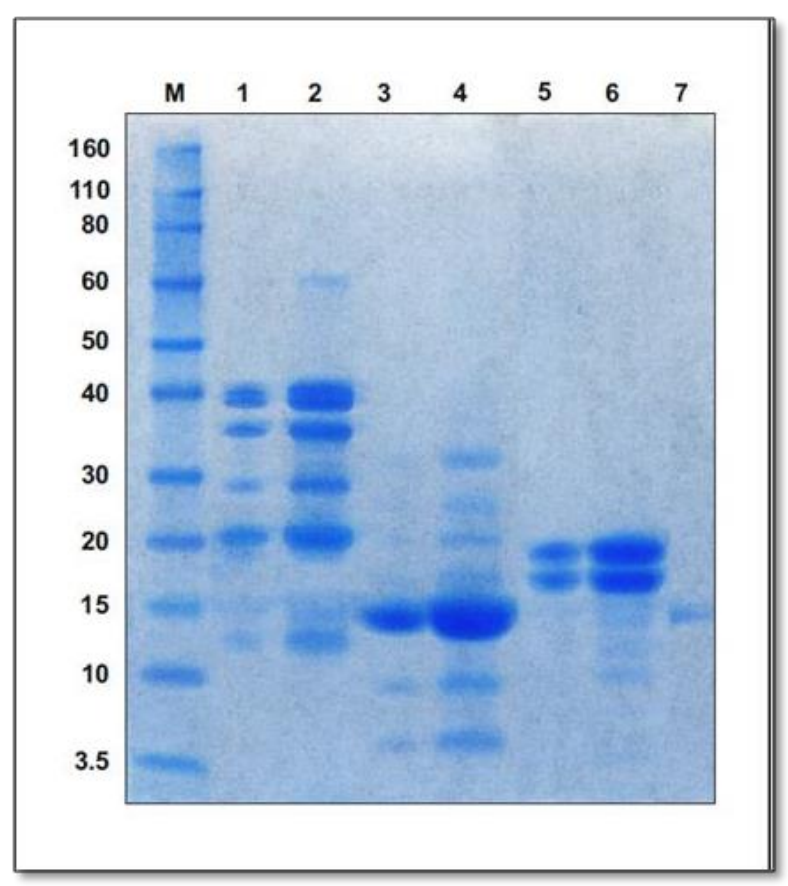

Fig .1 Protein banding pattern in P. Microphylla under different regimes of desiccation

M- Marker; (1) 1 D desiccated; (2) 1 D rehydrated; (3) 3 D desiccated; (4) 3 D rehydrated; (5) 5 D desiccated; (6) 5 D rehydrated; (7) 7 D desiccated

The 7 D desiccated plant generated only a single faint band at $15 \mathrm{kda}$. Interestingly the rehydrated plant showed no bands indicating the limitation of the species to drought stress i.e., maximum tolerance is up to $5 \mathrm{D}$ of desiccation. Similarly, Jyotiranjan rout et al., 2012 reported that in response to iron stress in Withaniasomnifera $L$. the SDS-PAGE profile showed a significant increase of protein content in leaves and roots up to a certain limit and then decreased.

\section{CONCLUSION}

This study has presented evidence that, $P$. microphylla are equipped to deal with abiotic stressdesiccation and subsequent rehydration environments up to $5 \mathrm{D}$. Changes in pigment composition and chloroplast thylakoids remained intact or distorted throughout the course of desiccation but regained during rehydration. Further studies are warrented for the characterization of stress related proteins.

\section{REFERENCES}

Ali Ahmad, M. and S.M., Basha (1998).Effect of water stress on composition of peanut leaves, Peanut Science, 25: 31-34.

Anderson, J.M., (1986). Photoregulation of the composition, function, and structure of thylakoid membranes, Annual Review of Plant Physiology, 37: 93-136.

Asha, S. and K. N., Rao, (2002). Effect of simulated water logging on the levels of amino acids in groundnut at the time of sowing, Indian Journal of Plant Physiology, 7: 288-291.

Basu, P.S., M. Ali and S.K. Chaturvedi, (2007). Osmotic adjustment increases water uptake, remobilization of assimilates and maintains photosynthesis in chickpea under drought, Indian Journal of Experimental Biology, 45: 261-267.

Bates, L. S., R.P. Waldron and I.D., Teare (1973). Rapid determination of free proline for water stress studies, Plant and Soil, 39: 205-208.

Beer, S., M. Bjork, F. Hellblom and L. Axelsson, (2002). Inorganic carbon utilization in marine angiosperms (sea grasses), Functional Plant Biology, 29: 349-354.

Bray, E.A., (1990). Drought-stress-induced polypeptide accumulation in tomato leaves, Plant Cell and Environment, 13: 531-538.

Chandrasekar, K.R. and S. Sandhyarani, (1996). Salinity induced chemical changes in Crotalaria striata DC. Plants, Indian Journal of Plant Physiology, 1: 44-48.

Chappelle, E.W., M. S. Kim and J.E.I. McMurtrey (1992). Ratio analysis of reflectance spectra (RARS): an algorithm for the remote estimation of the concentrations of chlorophyll $a$, chlorophyll $b$, and carotenoids in soybean leaves, Remote Sensing of Environment, 39: 239247.

Chen, T.H. and N. Murata, (2002). Enhancement of tolerance of abiotic stress by metabolic engineering of betaines and other compatible solutes, Current opinion in Plant Biology, 5: 250-257.

Davies, K.J.A., (1987). Protein damage and degradation by oxygen radicals. I. General aspects, J Biochem Chem., 262: 9895-9901.

Delauney, A.J. and D.P.S. Verma (1993). Proline biosynthesis and osmoregulation in plants, The Plant Journal, 4: 215-223. 
Demir, Y., (2000). Growth and proline content of germinating wheat genotypes under ultra violet light, Turkish Journal of Botany, 24: 67-70

Eder, A., W. Hubber and N. Sankhla, (1977). Interaction between salinity and ethylene in nitrogen metabolism of Pennisetumtyphoides seedling, Biochemie und Physiologie der Pflanzen, 171: 93-100

Fairbanks, V.F., J.L. Fahey and E. Beutter, (1971). Clinical disorders of iron metabolism Clinical 2nd Ed. Grune and Stratton N.Y Stratton, Inc: Newyork.

Frydman, J, (2001).Folding of newly translated proteins in vivo: the role of molecular chaperones, Annual Review of Biochemistry, 70: 603- 647.

Fujita, T., A. Maggio, M. G. Rios, R. C. Stauffache, R. A. Bressan and L. N. Csonka, (2003). Identification of regions of the tomato g-glutamyl kinase that are involved in allosteric regulation by proline, TheJournal of Biological Chemistry, 278: 1420314210.

Georgieva, K., E. Sarvari and A. Keresztes, (2010). Protection of thylakoids against combined light and drought by a luminal substance in the resurrection plant Haberlearhodopensis, Annals of Botany, 105: 117-126.

Girija, C., B.N. Smith and P.M. Swamy, (2002). Interactive effects of sodium chloride and calcium chloride on the accumulation of proline and glycinebetaine in peanut (ArachishypogaeaL.), Enviromental and Experimental Botany,43: 1-10.

Girousse, C., R. Bournoville and J. L., Bonnemain, (1996). Water deficit-induced changes in concentrations in proline and some other amino acids in the phloem sap of alfalfa, Plant Physiology, 111: 109-113.

Hamada, A.M., (2000). Amelioration of drought stress by ascorbic acid, thiamin and aspirin in wheat plants, Indian Journal of Plant Physiology, 5: 358-364.

Hartl, F.U., (1996). Molecular chaperones in cellular protein folding, Nature, 381: 571-580.

Hendry, G.A.F., (1993). Evolutionary origins and natural functions of fructans: a climatological, biogeography and mechanistic appraisal, New Phytologist, 123: 3-14.

Horton ruban, A.V. and R. G. Walters, (1996). Regulation of light harvesting in green plants, Annual Review of Plant Physiology and Plant Molecular Biology, 47: 655-684.
Jaleel, C.A., R. Gopi, B. Sankar, P. Manivannan, A. Kishorekumar, R. Sridharan and R. Panneerselvam, (2007c). Studies on germination, seedling vigour, lipid peroxidation and proline metabolism in Catharanthus roseus seedlings under salt stress, South African Journal of Botany, 73: 190-195.

Jyoti, R., and S. LataSahoo, (2012). Morphological and Protein Profile Alterations in Withinia somnifera $\mathrm{L}$. with response to iron stress, Indian Journal of Life Science, 2(1): 21-25.

Kaplan, F., and C.L. Guy, (2004). Beta-Amylase induction and the protective role of maltose during temperature shock, Plant Physiology ,135: 1674-1684.

Kasturibai, K.V. and V. Rajagopal, (2000). Osmotic adjustment as a mechanism for drought tolerance in coconut (CocosnuciferaL.), Indian Journal of Plant Physiology, 5: 320-323.

Kempa, S., J. Krasensky, S. Dal Santo , J. Kopka and C. Jonak, (2008). A central role of abscisic acid in stress-regulated carbohydrate metabolism, PLoS One, 3: e3935.

Laemmli, U.K., (1970). Clevage of structural proteins during the assembly of the head of bacteriophage T4, Nature, 227: 680-685.

Larosa, P.C., D. Rhodes, J.C. Rhodes, R.A. Bressan and L.N. Csonka, (1991). Elevated accumulation of proline in $\mathrm{NaCl}$ adapted tobacco cells is not due to altered pyrroline- 5-carboreylate reductase, Plant Physiology, 96: 245-250.

Leong, T.Y. and J.M. Anderson, (1983). Changes in composition and function of thylakoid membranes as a result of photosynthetic adaptation of chloroplasts from pea plants grown under different light conditions, Biochimica et BiophysicaActa, 723: 391-399.

Lin, C.C., Y.T.Hsu and C.H. Kao, (2002). The effect of $\mathrm{NaCl}$ on proline accumulation in riceleaves, Plant Growth Regulation, 36: 275-285.

Livingston, D.P., D.K. Hincha and A.G. Heyer, (2009). Fructan and its relationship to abiotic stress tolerance in plants, Cellular and Molecular Life Sciences, 66: 2007-2023.

Lowry, O.H., N.J. Rosebrough, A.L. Farr and R.J. Randall, (1951). Protein measurement with folin phenol reagent, Journal of Biology and Chemistry, 193: 265-295.

Ma, J.F., S.J. Zheng, S. Hiradate and H. Matsumoto, (1997b). Detoxifying aluminum with buck wheat, Nature, 390: 569-570.

Marschall, M. and M.C. Proctor, (2004). Are 
bryophytes shade plants? Photosynthetic light responses and proportions of chlorophyll $a$, chlorophyll $b$ and total carotenoids, Annals of Botany, 94: 593-603.

Miller, G.L., (1972). Analytical Chemistry, New York: McGraw Hill Book, p.426.

Moore, S. and W.H. Stein, (1948). Photometric ninhydrin method for use in the chromatography of amino acids, The Journal of Biological Chemistry, 176: 367-388.

Moran, J.F., M. Becana, I. Iturbe-Ormaetxe, S. Frechilla, R.V. Klucas and P. Aparicio-Tejo, (1994). Drought induces oxidative stress in pea plants, Planta, 194: 346-352.

Morgan, J.M. (1984). Osmoregulation and water stress in higher plants, Annual Review of Plant Physiology, 33: 299-319.

Nath, A.K., S. Kumari and D.R. Sharma, (2005). In vitro selection and characterization of water stress tolerant cultures of bell pepper, Indian Journal of Plant Physiology, 10: 14-19.

Olien, C.R. and J.L. Clark , (1995). Freeze-induced changes in carbohydrates associated with hardiness of barley and rye, Crop Science, 35: 496-502.

Oliver, M.J., J. Velten and B.D. Mischler, (2005). Desiccation tolerance in bryophytes: a reflection of a primitive strategy for plant survival in dehydrating habitats, Integrative and Comparative Biology, 45: 788-799.

Rao, G.G. and G.R. Rao, (1981). Pigment composition and chlorophyllase activity in pigeon pea (CajanusindicusSpreng) and Gingelley
(SesamumindicumL.) under $\mathrm{NaCl}$ salinity, Indian Journal of Experimental Biology, 19: 768-770.

Sharma, S.S. and K.J., Dietz, (2006). The significance of amino acids and amino acid-derived molecules in plant responces and adaptation to heavy metal stress, Journal of Experimental Botany, 57: 711-726.

Singh, A.K. and R.S., Dubey (1995). Changes in chlorophyll $a$ and $b$ contents and activities of photosystems I and II in rice seedlings induced by NaCl, Photosynthetica, 31: 489-499.

Spollen, W.G. and C.J., Nelson (1994). Response of fructan to water-deficit in growing leaves of tall fescue, Plant Physiology, 106: 329-336.

Tripathi, B.N. and J.P., Gaur (2004). Relationship between copper and zinc induced oxidative stress and proline accumulation in Scenedesmus sp., Planta, 219: 397-404.

Tuba, Z., M.C.F. Proctor and Z.S., Csintalan (1998). Ecophysiological responses of homoiochlorophyllous and poikilochlorophyllous desiccation tolerant plants: a comparison and an ecological perspective, Plant Growth Regulation, 24: 211217.

Yadav, S.K., N.J yothilakshmi, M. Maheswari, M. Vanaja and B., Venkateswarlu (2005). Influence of water deficit at vegetative, anthesis and grain filling stages on water relation and grain yield in sorghum, Indian Journal of Plant Physiology, 10: $20-24$. 